\title{
THE TECHNOLOGY BASED SECTORS IN MEXICO: AN ANALYSIS FOR THE FIRM SIZE AND
}

THE PRODUCTION SCALE

ALARCÓN-OSUNA, Moisés Alejandro ${ }^{1}$

DÍAZ-PEREZ, Claudia del Carmen²

\begin{abstract}
Many authors have remarked the importance of the Technology Based Firm (TBF) in the last years, in part due to factors like innovation, production scale, technological change and their flexibility in the production processes to create aggregate value. Instead of these arguments there is not a definition of the technology based sectors, these sectors and their technological level are described in this article. It is also analyzed the returns of scale and the size composition of these technological sectors, where it is shown that the technology based SMEs are as efficient as the large enterprises.

Key words: TBF, production scale, technology based sectors, SME firms, technological level. JEL Codes: C13, L11, L25, O33.
\end{abstract}

\section{Introduction}

Since the beginnings of the 1980's, the research on the TBF has taken off, due to factors like innovation, production scale, technological change and their flexibility in the production processes to create aggregate value (Bollinger, Hope and Utterback, 1983; Granstrand, 1998; Autio and Yli-Renko, 1998). An important fact is that the SME firms are in general the main sources of employment and economic growth (Kulicke and Krupp, 1987). The structure of the TBF is composed also by SME firms with the next distribution: 94\% Small, 5.5\% Medium and 0.5\% of Large firms, according to the estimations of Ganotakis and Love (2011). Nevertheless, it has been hard the measurement of the TBF participation on the economy of any country (Autio y Yli-Renko, 1998).

The productivity has turned into an additional argument for the research on the TBF (Ortrin and Vendrell, 2014; Yagüe and March, 2013; Li, Quian and Quian, 2012; Ganotakis and Love, 2011), mainly due to their knowledge based competitive advantage strategy (Granstrand, 1998; Autio and Yli-Renko, 1998; Colombo and Grilli, 2005; Coeurderoy and Murray, 2008; Fong and Alarcón, 2010), but also because this knowledge is incrusted in the workers, who have the capability to produce a bigger amount of goods with mayor value added and with relatively less capital factors.

Other authors like Granstrand (1998), Autio et al. (1998), Wu and Wang (2007), Ortrin and Vendrell (2014) point that the productivity of the TBF does not depend on the size of the firm, since a big proportion of the added value generated by these firms is incrusted in the knowledge inside of the products, which at the time allows to perform in a SME size achieving good results. Nevertheless, instead of the evidence that the TBF performs on increasing returns of scale due to this knowledge (Ortrin and Vendrell, 2014; Yagüe and March, 2013; Li, Quian and Quian, 2012; Ganotakis and Love, 2011), and in part due to the technological diversification (Tsvetkova, Thill and Strumsky, 2014; Li et. al, 2012; Patel y Pavitt, 1994; Pavitt, Robson and Townsend, 1989), there is a lack of consensus to define a clear taxonomy of the technology based sectors in which the TBF operates.

These kind of arguments have influenced the characterization of the TBF with different methodologies, some of these characterizations according to the technology that

1 Universidad Autónoma de Sinaloa, México, member of the National System of Researchers of the National Consul of Science and Technology (CONACYT), contact alarcon93@ hotmail.com.

2 Universidad Autónoma Metropolitana, México, member of the National System of Researchers of the National Consul of Science and Technology (CONACYT), contact claudp33@yahoo.com. 
employ these firms. Butchart (1987) and Lall (2000) have defined the technology based sectors as those with high and low technological level, based in the spend level on R\&D and the economic growth on relatively short time periods. Other authors have made some measurements pointing the importance of variables like age, number of workers, education and gender of managers and workers (Breschi, Lenzi, Malerba and Mancusi, 2014; Ejermo and Xiao, 2013; Yagüe and March, 2013; Kollmer and Dowlin, 2004; Granstrand, 1998; Storey and Tether, 1998a, 1998b; Bollinger et al, 1983). Other kind of research remark the instable environment in which the TBF performs (Teixeira and Tavares, 2014; Clarysse, Bruneel and Wright, 2011; Suzuki, Teixeira, Ferreira and Real, 2011; Aspelund, Berg and Skjevdal, 2005; Kollmer and Dowlin, 2004; Granstrand, 1998). Also it has been studied the risk of the technological diversification over the sales (Kulicke and Krupp, 1987; Fontes and Coombs, 2001; Li et al. 2012; Onetti, Zucchella, Jones and McDougall, 2012). Other authors made a clear differentiation on the performance of an independent TBF and the University Spin-Off where the last is constituted from the knowledge and support of the University or Research Institute (Ortrin and Vendrell, 2014; Suzuki et al., 2011).

These variables play an important role on the definition of a TBF, but still it is not clear the definition of a technology based sector, nevertheless there is some other studies where it has been tried to establish a taxonomy of these sectors. In the present article it is proposed a classification of these sectors for making more precise estimations of these kind of firms and their impact on the national economy.

As it has been noted, the SMEs play an important role in the definition of the TBF. Nevertheless, it is a lack of research on the impact of these firms in the performance of the technology based sectors. Since 1980 it has been pointed out the importance of the small firm on the performance of the TBF (Bollinger et al., 1983; Kulicke and Krupp, 1987) due to their flexibility to innovate. But also it has been outstand the role of the technology based SME on the creation of employs and the economic growth (Rae, 2006; Ganotakis and Love, 2011; Li et al., 2012), as well as the technological dissemination (Tsvetkova et al. 2014).

For those reasons, in this article it is proposed a regression model with a CobbDouglass estimation for making inference on the factorial productivity of the capital and work. This estimation allows to analyze the difference in the marginal returns of the different size of TBF, and by another hand it will be showed the influence of the different technology based sectors and the firm size in the technological level of the TBF. This argument agrees with the identified literature, which points that it is not necessary for the TBF to achieve a massive production scale for achieving at the same time the success in sales (Ortrin and Vendrell, 2014; Yagüe and March, 2013; Li et al., 2012; Ganotakis and Love, 2011; Wu and Wang, 2007; Granstrand, 1998; Autio et al., 1998). By last, it is described how has been the evolution of the TBF performance by size, since the SME in México constitutes more than $98 \%$ of the total firms.

\section{Technology based sectors classification}

The formal definition of a TBF is constituted by firms of no more than 25 years old, which depend on the exploiting of an innovation or invention that implies a substantial technological risk (Storey and Tether, 1998a). Inside this definition, there is not only technology, since this technology must be recent, and by another side it suppose the exploiting of a business opportunity that also implies a risk (Onetti et al. 2012; Lockett and Wright, 2005; Kollmer and Dowling, 2004; March and Yagüe, 1999), this is the risk associated to the leading edge technologies.

One of the fundamental questions for studying the TBF is to define the sectors in which they perform, but also to define the taxonomy in a sector characterization. In some of 
the first approaches Bollinger et al. (1983) studied the sectors conformed by the semiconductor, integrated circuits, software, medical equipment and aerospatiale. Kulicke and Krupp (1987) studied the electronic sectors, computers, robotics, measurement equipment and laser manufactures. As it can be seen in this kind of studies, the definition of a technology based sector is based in the leading edge sectors in a specific period of time, but without establishing a consensus over the characteristics of a technology based sector.

Other studies like those made by Autio and Yli-Renko (1998) identify the next sectors: forestall, metallurgic, telecommunications, electronics, medic, biotechnologies, energy, transports, environment, food, dress and clothes, etc. These sectors where found based on the main clients of the TBFs, suggesting the study of the TBF like the industrial sectors that conform the technology based sectors. Other kind of studies, take as reference the amount of spending in R\&D like Butchart (1987) and Lall (2000) where it has been made a classification of the technology based sectors to describe the exporting performance of the countries. It is identified four sectors according to the technology level from low to high:

1- Sectors based on the exploiting of natural resources.

2- Manufactures with low tech level.

3- Manufactures with medium tech level.

4- Manufactures with high tech level.

The main limitation of this system of classification, is the fact that it only takes into account the sophistication level of the production machines. Nevertheless, the manufactures with high tech level of Butchart and Lall are not necessarily manufactures of a TBF, since they are not coming from a new technology that is pointing to get a new business opportunity.

Other studies define the technology based sectors as: telecommunications, hardware, software, internet, semiconductors, biotechnologies, medic technologies, chemical and pharmaceutical, measurement equipment, lazer technologies, nanotechnologies, microelectronic and aeroespatiale (Tsvetkova et al., 2014; Oakey, Groen, Cook y Van Der Sijde, 2013; Onetti et al., 2012; Li et al., 2012; Kollmer and Dowlin, 2004; Fontes and Coombs, 2001). In the major part of the cases, these taxonomies match with the definitions of Autio et al. (1998). Nevertheless, these sectors must be on a specific context due to the different cultures and economic environment of each country, but also due to the technological intensity of each sector. These factors play a special role as it is pointed by some authors (Butchart, 1987; Storey y Tether, 1998a; Lall, 2000). Taking as reference all the things pointed before, we can classify the technology based sectors in four:

- Telecommunications and information technologies.

- Electronic and vehicular technologies.

- Biotechnologies and medic technologies.

- Chemical and pharmaceutical.

This classification will be the base of this work and it will be described in the next sections.

\section{The problem}

A propose of this work is to identify the technology based sectors in the Mexican context, and to analyze what would be the impact of these sectors in the national economy. Additionally it is stated the need to recognize if the TBFs performs with scale economies, since this would demonstrate that not necessarily this kind of firms must to work with economies of scale to achieve the business success. In this way, it is pretend to show that the public policy design is 
needed to encourage these sectors in large sized firms but also in SME technology based firms. Due the last explanation, the hypothesis of this work is as follows:

- The increasing returns of scale are not a determinant for the TBF success.

- The TBF technological level is determined by the technology based sector in which the firm is working.

These hypothesis suggest that not necessarily the large-sized TBF is that which has the highest technological level. The flexibility of the SME TBT allows to work with returns seemingly equal to the large-sized firm. By the other side it is remarked the importance that has the innovation, since this kind of firm don't require increasing returns of scale to achieve big production volumes and to achieve the business success.

\section{Methodology and database of this research}

Starting from the four sectors previously defined as the technology based sectors that take into account the North America Industrial Classification System (NAICS) that takes the National Institute of Statistics, Geography and Informatics (NISGI) as a base to identify the TBFs into the Mexican context ${ }^{3}$. It is considered the data from the economic census of 2004 and 2009 since these census has the most updated disposable information. It is from this data that is made a description of the evolution that has follow the TBF, but also it is made some inference about the way in which these firms perform.

\section{Characterization of the technology based sectors}

According to the NAICS, and according to the definitions given in the first sections, it is classified in table 1 the technology based sectors (see Table 1 in appendix). In this way, it is disaggregated the industrial technology based sectors in Mexico, identifying four big sectors, the same sectors that were signed in the second section.

\section{Regression model}

In this work it is estimated the Cobb-Douglass production function with the data from the economic census of 2004 and 2009. Nevertheless, it is important to sign that in other studies of TBF productivity it has been used the regression models, but not to make comparisons over the TBF in their different sizes (Yagüe and March, 2013; Li et al, 2012; Ganotakis and Love, 2011), except Ortrin and Vendrell (2014) who compares the TBF with the University Spin-Offs.

This estimation will allow us to define if in the different sizes of TBF exist economies with increasing returns of scale, since one of the hypothesis is the existence of this kind of returns in the technology based sectors. The econometric model is the next:

$$
\log (\mathrm{Y})=\beta 1 * \operatorname{Sector}+\beta 2 *[\log (\mathrm{L}) * \operatorname{Size}]+\beta 3 *[\log (\mathrm{K}) * \operatorname{Size}]+\mathrm{e}
$$

Where "Log(Y)" represents the $\log$ of the production, "Log $(\mathrm{L})$ " the log of labor, " $\log (\mathrm{K})$ ” is the log of capital, "Sector" is a dummy variable that represents the technological sector, and "Size" is also a dummy variable that represents the size of the firm. This econometric model allow us to verify the existence of economies of scale due to the next condition: If $(\beta 2+\beta 3)$ is equal to one then it exist economies of scale, if the condition is major than one then it exist

\footnotetext{
3 It is not new to use the NAICS to identify the technology based sectors, since other studies like Tsvetkova et al (2014) use this classification system to identify the sectors of computer, communication, audio, video, travel equipment and optical equipment.
} 
increasing returns of scale, the two conditions will show that the firm makes an efficient use of the production factors.

We have different proxy variables for production, labor and capital, since there exist two kind of variables (static and dynamic).

For the production variable we have as a static variable the Total Domestic Product, and as a dynamic variable we have the Censal Gross Added Value.

For the labor the static proxy variable is the occupied personal and as a dynamic variable the hours worked.

Finally for the capital we have as a static variable the total fixed assets and as a dynamic variable the gross fixed capital formation. This information is given in Table 2 (see appendix).

The registers that would be taken into account for this estimation are representative firms for each strata of firm size. In this way we can accede to the databases trough NISGI and the economic census, with classifications by number of employees as it is show in Table 3 (see appendix).

\section{Results and relevant statistics}

With the aim to understand the behavior and paths that has followed the technology based sector in Mexico, it is shown the contribution of the TBF to the total national production in 2004 and 2009, since with only $2 \%$ of the total firms, they produce around $20 \%$ of the gross national production, with just $8.5 \%$ of the total workers, this results are shown in Table $4^{4}$.

Table 4. Contribution of the technology based sectors to the total national.

\begin{tabular}{|c|c|c|c|c|c|c|}
\hline \multirow[b]{2}{*}{$\begin{array}{l}\text { Technological Sector } \\
\text { Economic Cencus }\end{array}$} & \multicolumn{2}{|c|}{$\begin{array}{l}\text { Number of } \\
\text { Firms }\end{array}$} & \multicolumn{2}{|c|}{ Workers } & \multicolumn{2}{|c|}{$\begin{array}{c}\text { Total Gross } \\
\text { Production } \\
\text { (thousands of pesos) }\end{array}$} \\
\hline & 2004 & 2009 & 2004 & 2009 & 2004 & 2009 \\
\hline Telecom. and ITCs & $6.66 \%$ & $9.38 \%$ & $24.09 \%$ & $24.21 \%$ & $14.52 \%$ & $8.21 \%$ \\
\hline $\begin{array}{l}\text { Electronics and Vehicular } \\
\text { equipment }\end{array}$ & $\begin{array}{c}61.37 \\
\%\end{array}$ & $\begin{array}{c}54.41 \\
\%\end{array}$ & $33.70 \%$ & $34.52 \%$ & $17.53 \%$ & $16.59 \%$ \\
\hline Biotec. and Medical Tech & $\begin{array}{c}19.28 \\
\%\end{array}$ & $\begin{array}{c}24.11 \\
\%\end{array}$ & $8.92 \%$ & $10.82 \%$ & $7.77 \%$ & $7.82 \%$ \\
\hline Chemical and Pharmaceutical & $\begin{array}{c}12.68 \\
\%\end{array}$ & $\begin{array}{c}12.10 \\
\%\end{array}$ & $33.29 \%$ & $30.45 \%$ & $60.17 \%$ & $67.38 \%$ \\
\hline Total Technology sectors & 60,813 & 76,242 & $\begin{array}{c}1,384,0 \\
50\end{array}$ & $\begin{array}{c}1,643,7 \\
96\end{array}$ & $\begin{array}{c}1,210,288 \\
, 237\end{array}$ & $\begin{array}{l}2,315,008, \\
897\end{array}$ \\
\hline Total Mexico & $\begin{array}{c}3,002, \\
720\end{array}$ & $\begin{array}{c}3,721 \\
430\end{array}$ & $\begin{array}{l}16,018 \\
201\end{array}$ & $\begin{array}{c}19,881 \\
146\end{array}$ & $\begin{array}{l}5,974,656 \\
, 821\end{array}$ & $\begin{array}{c}10,480,98 \\
0,684\end{array}$ \\
\hline $\begin{array}{l}\text { Participation of the TBF to the } \\
\text { Total Mexico }\end{array}$ & $2.03 \%$ & $2.05 \%$ & $8.64 \%$ & $8.27 \%$ & $20.26 \%$ & $22.09 \%$ \\
\hline
\end{tabular}

4 It must be taken into account that the economic census doesn't take for the measures the informal activities, nether the primary activities, taking only into account the manufactures and services industries. 
By another side, doing a description by firm size in the same technology based sectors we have the next information, that shows that the SME sums around 98\% of the total TBFs, with $43 \%$ of the total workers, and most important generating the $25 \%$ of the total TBF production. It can be concluded that the TBF and the technology based sectors constitutes an important proportion of the national production, nevertheless the participation of the SME technology based firms is relatively small in comparison to the production of the large firms, since having $98 \%$ of the total firms they are producing only the $25 \%$, this data is shown in Table 5.

Table 5. Participation by TBF size.

\begin{tabular}{|c|c|c|c|c|c|c|}
\hline TBF & \multicolumn{2}{|c|}{$\begin{array}{c}\text { Firms } \\
\mathbf{\%}\end{array}$} & \multicolumn{2}{c|}{$\begin{array}{c}\text { Workers } \\
\text { \% }\end{array}$} & \multicolumn{2}{c|}{$\begin{array}{c}\text { Total Gross Production } \\
\text { (million of pesos) }\end{array}$} \\
\hline $\begin{array}{c}\text { Firm Size / Economic } \\
\text { Census }\end{array}$ & $\mathbf{2 0 0 4}$ & $\mathbf{2 0 0 9}$ & $\mathbf{2 0 0 4}$ & $\mathbf{2 0 0 9}$ & $\mathbf{2 0 0 4}$ & $\mathbf{2 0 0 9}$ \\
\hline Micro & $81.90 \%$ & $83.50 \%$ & $9.62 \%$ & $10.60 \%$ & $2.36 \%$ & $1.43 \%$ \\
\hline Small & $11.55 \%$ & $10.81 \%$ & $11.27 \%$ & $10.98 \%$ & $6.05 \%$ & $4.93 \%$ \\
\hline Medium & $4.75 \%$ & $4.07 \%$ & $23.45 \%$ & $21.32 \%$ & $17.89 \%$ & $16.85 \%$ \\
\hline Large & $1.80 \%$ & $1.63 \%$ & $55.66 \%$ & $57.10 \%$ & $73.70 \%$ & $76.79 \%$ \\
\hline Total & 60813 & 76242 & 1384050 & 1643796 & 1210288 & 2315009 \\
\hline
\end{tabular}

\begin{tabular}{|c|c|c|c|c|c|c|c|c|}
\hline \multirow{4}{*}{\begin{tabular}{|l} 
Dependent variable \\
Log(HORAS)*SIZE1
\end{tabular}} & \multicolumn{8}{|c|}{ Census 2004} \\
\hline & \multicolumn{2}{|c|}{ Log(PROD) } & \multirow{2}{*}{\multicolumn{2}{|c|}{\begin{tabular}{|c|} 
Log(VA) \\
Coef.S.E.
\end{tabular}}} & \multirow{2}{*}{\multicolumn{2}{|c|}{\begin{tabular}{|c|} 
Log(PROD) \\
Coef.S.E.
\end{tabular}}} & \multirow{2}{*}{\multicolumn{2}{|c|}{\begin{tabular}{|c|} 
Log(VA) \\
Coef. $\mid$ S.E. \\
\end{tabular}}} \\
\hline & Coef. & S.E. & & & & & & \\
\hline & $0.73^{* * *}$ & * 0.07 & 0.83 & $0.09 * * *$ & & & & \\
\hline Log(FBCF)*SIZE1 & 0.25 *** & $\begin{array}{ll}* & 0.05 \\
\end{array}$ & 0.19 & 0.07 ** & & & & \\
\hline Log(HORAS)*SIZE2 & $0.87 * * *$ & 0.05 & 0.85 & $0.07 * * *$ & & & & \\
\hline Log(FBCF)*SIZE2 & 0.17 *** & $\begin{array}{ll}* & 0.04 \\
\end{array}$ & 0.22 & $0.06^{* * *}$ & & & & \\
\hline Log(HORAS)*SIZE3 & 0.84 *** & \begin{tabular}{l|l}
$*$ & 0.10
\end{tabular} & 0.88 & $0.09 * * *$ & & & & \\
\hline Log(FBCF)*SIZE3 & $0.22 * *$ & 0.09 & 0.21 & $0.07 * *$ & & & & \\
\hline Log(HORAS)*SIZE4 & 0.74 *** & 0.05 & 0.82 & $0.06^{* * *}$ & & & & \\
\hline Log(FBCF)*SIZE4 & 0.32 *** & 0.04 & 0.28 & $0.05^{* * *}$ & & & & \\
\hline Log(PO)*SIZE1 & & & & & 0.73 & $0.13^{* * *}$ & 0.73 & $0.14^{*}$ \\
\hline Log(ACERVO)*SIZE1 & & & & & 0.33 & $0.10^{* * * *}$ & 0.33 & 0.11 ** \\
\hline Log(PO)*SIZE2 & & & & & 0.68 & $0.11 * * *$ & 0.63 & $0.09 * * *$ \\
\hline Log(ACERVO)*SIZE2 & & & & & 0.40 & $0.09 * * *$ & 0.43 & $0.08^{* * * *}$ \\
\hline Log(PO)*SIZE3 & & & & & 0.61 & $0.12^{* * *}$ & 0.62 & $0.14^{* * * *}$ \\
\hline Log(ACERVO)*SIZE3 & & & & & 0.44 & $0.08^{* * *}$ & 0.44 & $0.09^{* * *}$ \\
\hline Log(PO)*SIZE4 & & & & & 0.44 & $0.10^{* * * *}$ & 0.65 & $0.09 * * *$ \\
\hline Log(ACERVO)*SIZE4 & & & & & 0.56 & $0.07 * * *$ & 0.44 & $0.06^{* * *}$ \\
\hline SEC1 & 4.51 & $0.22 * * *$ & 3.38 & $0.27 * * *$ & 3.51 & $0.41 * * *$ & 2.58 & $0.44 * * *$ \\
\hline SEC2 & 4.40 & $0.23 * * *$ & 3.23 & $0.27 * * *$ & 3.48 & $0.41 * * *$ & 2.51 & $0.43^{* * * *}$ \\
\hline SEC3 & 4.14 & $0.29 * * *$ & 2.77 & $0.34^{* * *}$ & 3.22 & $0.46^{* * *}$ & 2.16 & $0.48^{* * *}$ \\
\hline SEC4 & 4.79 & $0.26 * * *$ & 3.33 & $0.33^{* * *}$ & 3.70 & $0.47 * * *$ & 2.51 & $0.50^{* * *}$ \\
\hline & & & & & & & & \\
\hline R-squ & & 0.90 & & 0.87 & & 0.92 & & 0.88 \\
\hline Adjusted R-squared & & 0.90 & & 0.87 & & 0.92 & & 0.88 \\
\hline S.E. of regression & & 0.69 & & 0.81 & & 0.67 & & 0.80 \\
\hline Sum squared resid & & 234.98 & & 308.41 & & 250.92 & & 338.99 \\
\hline Log likelihood & & -524.99 & & -579.09 & & -571.89 & & -639.14 \\
\hline Obs & & 508 & & 486 & & 564 & & 538 \\
\hline
\end{tabular}


These results reinforce the hypothesis of Breschi et al. (2014), Aspelund et al. (2005) and $\mathrm{Li}$ et al. (2012) who consider that the TBF encourage the technological change and by this means the creation of new products, process, markets and organizational structures. Taking with some carefully the data, it is inferred that this huge quantity of technology based SMEs are generating the technological change, and given the risk that implies to start this kind of business the participation of these firms to the total technology based sectors are small (25\% of the total production).

Taking as reference the regression analysis and the Cobb-Douglas estimation, the results shows that all the firm sizes performs with increasing returns of scale for the year 2004 , but for the 2009 the returns are lower. These results additionally shows that for the economic census of 2009 only the large size firms (SIZE4) performs efficiently, and the size of firm that was capable to sustain a similar perform was the small firm (SIZE2). Another interesting analysis for the regression model is that the TBF in the sector 4 (Chemical and Pharmaceutical "SEC4) have the highest technological level (See Table 6), and the second technological level is given in sector 1 (Telecommunications and ITC "SEC1"), nevertheless for the economic census of 2009 the sector of Chemical and Pharmaceutical has a highest technological level far from the rest of the sectors.

Tabla 6. Resultados del Análisis de regresión y la estimación Cobb-Douglas

\begin{tabular}{|c|c|c|c|c|c|c|c|c|}
\hline \multirow{4}{*}{$\begin{array}{l}\text { Dependent variabl } \\
\text { Log(HORAS)*SIZE1 }\end{array}$} & \multicolumn{8}{|c|}{ Census 2009} \\
\hline & \multirow{2}{*}{\multicolumn{2}{|c|}{\begin{tabular}{|l|} 
Log(PROD) \\
Coef.S.E. \\
\end{tabular}}} & \multirow{2}{*}{\multicolumn{2}{|c|}{\begin{tabular}{|c|} 
Log(VA) \\
Coef.|S.E. \\
\end{tabular}}} & \multirow{2}{*}{\multicolumn{2}{|c|}{\begin{tabular}{|l|} 
Log(PROD) \\
Coef.|S.E.
\end{tabular}}} & \multirow{2}{*}{\multicolumn{2}{|c|}{\begin{tabular}{|c|} 
Log(VA) \\
Coef.|S.E.
\end{tabular}}} \\
\hline & & & & & & & & \\
\hline & 0.61 & $0.07 * * *$ & 0.61 & $0.08^{* * * *}$ & & & & \\
\hline Log(FBCF)*SIZE1 & 0.19 & $0.06^{* *}$ & 0.23 & $0.07 * *$ & & & & \\
\hline Log(HORAS)*SIZE2 & 0.62 & $0.08^{* * *}$ & 0.68 & $0.08^{* * *}$ & & & & \\
\hline Log(FBCF)*SIZE2 & 0.25 & $0.06^{* * *}$ & 0.24 & $0.06^{* *}$ & & & & \\
\hline Log(HORAS)*SIZE3 & 0.65 & $0.07 * * *$ & 0.74 & $0.07 * * *$ & & & & \\
\hline Log(FBCF)*SIZE3 & 0.27 & $0.06^{* * *}$ & 0.23 & $0.05^{* * *}$ & & & & \\
\hline Log(HORAS)*SIZE4 & 0.61 & $0.06^{* * *}$ & 0.71 & $0.06^{* * *}$ & & & & \\
\hline Log(FBCF)*SIZE4 & 0.31 & $0.05^{* * *}$ & 0.26 & $0.05^{* * * *}$ & & & & \\
\hline Log(PO)*SIZE1 & & & & & 0.51 & $0.11^{* * * *}$ & 0.63 & $0.12^{* * *}$ \\
\hline Log(ACERVO)*SIZE1 & & & & & 0.39 & $0.08^{* * * *}$ & 0.29 & $0.08^{* *}$ \\
\hline Log(PO)*SIZE2 & & & & & 0.61 & $0.10^{* * * *}$ & 0.73 & $0.11^{* * *}$ \\
\hline Log(ACERVO)*SIZE2 & & & & & 0.39 & $0.07 * * *$ & 0.29 & $0.08^{* *}$ \\
\hline Log(PO)*SIZE3 & & & & & 0.53 & $0.10^{* * * *}$ & 0.48 & $0.08^{* * *}$ \\
\hline Log(ACERVO)*SIZE3 & & & & & 0.46 & $0.06^{* * * *}$ & 0.47 & $0.05^{* * *}$ \\
\hline Log(PO)*SIZE4 & & & & & 0.49 & $0.08^{* * * *}$ & 0.69 & $0.08^{* * *}$ \\
\hline Log(ACERVO)*SIZE4 & & & & & 0.49 & $0.05^{* * * *}$ & 0.35 & $0.06^{* * *}$ \\
\hline SEC1 & 5.99 & $0.24^{* * *}$ & 4.72 & $0.30 * * *$ & 4.25 & $0.28^{* * * *}$ & 3.56 & $0.35^{* * *}$ \\
\hline SEC2 & 5.90 & $0.25^{* * *}$ & 4.60 & $0.30 * * *$ & 4.11 & $0.27 * * *$ & 3.48 & $0.32^{* * *}$ \\
\hline SEC3 & 5.57 & $0.33^{* * *}$ & 4.17 & $0.38^{* * * *}$ & 3.77 & $0.34^{* * * *}$ & 3.12 & $0.39 * * *$ \\
\hline SEC4 & 6.66 & $0.30^{* * *}$ & 5.16 & $0.34^{* * *}$ & 4.62 & $0.33^{* * * *}$ & 3.88 & $0.37 * * *$ \\
\hline & & & & & & & & \\
\hline R-squared & & 0.87 & & 0.86 & & 0.90 & & 0.88 \\
\hline Adjusted R-squared & & 0.87 & & 0.86 & & 0.90 & & 0.88 \\
\hline S.E. of regression & & 0.78 & & 0.82 & & 0.75 & & 0.81 \\
\hline Sum squared resid & & 299.15 & & 316.55 & & 309.59 & & 347.99 \\
\hline Log likelihood & & -583.69 & & -584.01 & & -632.99 & & -646.19 \\
\hline Obs & & 504 & & 484 & & 567 & & 538 \\
\hline
\end{tabular}

It is shown the coefficients and standar errors, showing * when the significance level is $10 \%$, ** for $5 \%$, *** for $1 \%$. 
It can be seen in the results of Table 6 that in the major part of the regression equations in the economic census of 2004 there exist increasing returns of scale. As an example the sum of the coefficients (LOG(HOURS)*SIZE2 + LOG(GFCF)*SIZE2) from the first regression (0.87 $+0.17=1.04$ ), there are increasing returns of scale. This implies that this strata of firm performs efficiently. By another side, in all the regressions, it is estimated that the technological level on the chemical and pharmaceutical is higher than the rest of the sectors. Even, it can be said that the chemical and pharmaceutical sector have increased the technological level from the first to the second census.

From the last results, it can be inferred that the TBF of small size can sustain an efficient performance just as the large size does, therefore there isn't a disadvantage in the productive scale from one size to another. Another interesting fact is that the TBF that are in the chemical and pharmaceutical sector has a higher technological level, even if it is measured with dynamic or static variables.

\section{Concluding comments}

The hypothesis of this work point that the productive scale of the technology based SME is efficient, arguing that the increasing returns are not a determinant of the success of this kind of firm, and also arguing that the technological sector is a key determinant of the technological level of the firm. In both cases it was corroborated that the SME firm is working with an efficient scale, but also this efficient performance is comparable to the performance of the large TBF.

By another side, an interesting result is that these technology based sector made an important contribution to the total manufactures and services in the economic census. For both periods the total production was over $20 \%$ of the total, with just $2 \%$ of the total number of firms and $8.2 \%$ of the total workers. Equally important is the fact that the major part of these firms were micro-sized firms (less than 10 employees).

Some limitations of the study is in first place the update of the survey (2009), since the next survey results are going to be published on January 2015. Additionally another limitation in the regression model is that olnly were taken into account the capital and labor as productive factors. Nevertheless the results are significant.

Some future research could be the influence of variables like te internationalization of the firm and the technology transfer between TBF, since an important characteristic of this kind of firms is that they tend to participate in the international markets, but also they tend to cooperate or establish networks with other firms or institutions to transfer technology and then innovate in products and/ or services.

\section{References}

Aspelund, A; Berg, T and Skjevdal, R (2005). “Initial resources' influence on new venture survival: a longitudinal study of new technology-based firms", Technovation, Vol. 25; 1337-1347.

Autio, E. and Yli-Renko, H. (1998). "New, technology-based firms in small open economies -An analysis based on the Finnish experience", Research Policy, Vol. 26; 973-987.

Barney, J.B., (1986). "Strategic factor markets: expectations, luck, and business strategy". Management Science, Vol. 32; 1231-1241.

Bollinger, L; Hope K. and Utterback, J (1983). "A review of literature and hypothesis on new technology based firms", Research Policy, Vol. 12; 1-14.

Breschi, S; Lenzi, C; Malerba, F and Mancusi, M. (2014). "Knowledge-intensive entrepreneurship: sectoral patterns in a sample of European high-tech firms", Technology Analysis \& Strategic Management, 1-14. 
Butchart, R., (1987). “A new UK definition of high technology industries”. Econ. Rev. Vol. 400; 8288.

Clarysse, B; Bruneel, J and Wright, M (2011). "Explaining growth paths of young technology-based firms: structuring resource portfolios in different competitive environments", Strategic Entrepreneurship Journal, Vol. 5; 137-157.

Coase, R. (1937). "The nature of the firm", Economica London School of Economics, Vol. 4.

Coeurderoy, R. and Murray, G. (2008). "Regulatory environments and the location decision: evidence from the early foreign market entries of new-technology-based firms", Journal of International Business Studies, Vol. 39; 670-687.

Colombo, M. and Grilli, L. (2005). "Founders' human capital and the growth of new technologybased firms: A competence-based view", Research Policy, Vol. 34; 795-816.

Dierickx, I. and Cool, K., (1989). "Asset stock accumulation and sustainability of competitive advantage". Management Science, Vol. 35; 1504-1513.

Ejermo, Olof and Xiao, Jing (2014). "Entrepreneurship and survival over the business cycle: how do new technology-based firms differ?", Small Bus Econ, Vol. 1; 1-16.

Fong, C. R. and Alarcón, M.A. (2010). "Funcionamiento de empresas de base tecnológica: obtención de recursos estratégicos en las junturas críticas", Revista Internacional de Administración y Finanzas, Vol. 3; 39-54.

Fontes, M and Coombs R (2001). "Contribution of new technology-based firms to the strengthening of technological capabilities in intermediate economies", Research Policy, Vol. 30; 79-97.

Ganotakis, Panagiotis and Love, James (2011). "R\&D, product innovation, and exporting: evidence from UK new technology based firms", Oxford Economic Papers, Vol. 63; 279-306.

Granstrand, Ove. 1998. "Towards a theory of the technology-based firm”, Research Policy, Vol. 27; 465-489.

Grant, R.M., 1991. "The resource-based theory of competitive advantage: implications for strategy formulation". California Management Review, Vol. 33; 114-135.

Instituto Nacional de Estadística y Geografía; Censos Económicos de 2009. Accesed January of 2014. http:// www.inegi.org.mx/ est/ contenidos/Proyectos/ ce/ default.aspx.

Kollmer, Holger and Dowling, Michael (2004). "Licensing as a commercialisation strategy for new technology-based firms”, Reseach Policy, Vol. 33; 1141-1151.

Kulicke, Marianne and Krupp, Helmar (1987). "The formation, relevance and public promotion of new technology-based firms", Technovation, Vol. 6; 47-56.

Lall, S. (2000), "The Technological Structure and Performance of Developing Country Manufactured Exports, 1985-98”, Oxford Development Studies, Vol. 28; 337-369.

Li, Lee; Quian, Gongming and Quian, Zhengming (2012). "The performance of small and mediumsized technology-based enterprises: Do product diversity and international diversity matter?", International Business Review, Vol. 21; 941-956.

Lockett, A. and Wright, M. (2005). "Resources, capabilities, risk capital and the creation of university spin-out companies". Research Policy, Vol. 34; 1043-1057.

March, Isidre and Yagüe Rosa (1999). "A new tool to classifying new technology based firm prospect and expectations", the journal of high technology management research, Vol. 10; 347-376.

Patel, P. and Pavitt, K., (1994). "Technological Competencies in the World's Largest Firms: Characteristics, Constraints and Scope for Managerial Choice". STEEP Discussion Paper No. 13, Science Policy Research Unit, University of Sussex. 
Pavitt, K., Robson, M., Townsend, J., (1989). “Technological accumulation, diversification and organisation in UK companies. 1945-1983". Management Science, Vol. 35.

Oakey, R; G, A.; Cook, G. Van Der Sijde, P. (1993). New Technology Based Firms in the New Millennium, Emerald Book series, Vol. 1.

Onetti, A; Zucchella, A; Jones, M and McDougall, P (2012). "Internationalization, innovation and entrepreneurship: business models for new technology-based firms”, J Manag Gov, Vol. 16; 337-368.

Ortin, Pedro and Vendrell, Ferran (2014). "University spin-offs vs. other NTBFs: Total factor productivity differences at outset and evolution", Technovation, Vol. 34; 101-112.

Rae, David (2007). "Entrepreneurial learning: A conceptual framework for technology-based enterprise", Technology Analysis \& Strategic Management, Vol. 18; 39-56.

Solow, R.M. (1957). "Technical Change and the Aggregate Production Function". The Review of Economics and Statistics, Vol. 39; 312-320.

Storey, D.J. and Tether, B.S. (1998a). "New technology-based firms in the European Union: an introduction", Research Policy, Vol. 26; 933-946.

Storey, D.J. and Tether, B.S. (1998b). "Public policy measures to support new technology-based firms in the European Union", Research Policy, Vol. 26; 1037-1057.

Suzuki, R. de Oliveira; Teixeira A. de Freitas; Ferreira, M.; and Real N. (2011). "Analysis of Competences for Innovation in Technology-Based Enterprise Incubators", Latin American Business Review, Vol. 12; 187-207.

Teixeira, Aurora and Tavares, Teresa (2014). "Human capital intensity in technology-based firms located in Portugal: Does foreign ownership matter?”, Research Policy, Vol. 43; 737-748.

Tsvetkova, Alexandra; Thill, Jean and Strumsky, Devorah (2014). "Metropolitan innovation, firm size, and business survival in a high-tech industry", Small Bus Econ: 1-16.

Wernerfelt, B., (1984). "A resource-based view of the firm”, Strategic Management Journal, Vol. 5; 171-180.

Wu, Lei-Yu and Wang, Chun-Ju. (2007). "Transforming resources to improve performance of technology-based firms: A Taiwanese Empirical Study", Journal of Engineering and Technology Management, Vol. 24; 251-261.

Yagüe, RM and Mach, IC (2013). "Performance analysis of NTBFs in knowledge-intensive industries: Evidence from the human health sector", Journal of Business Research, Vol. 66; 1983-1989.

\section{Appendix}

Table 1. Technology Based Sectors

\begin{tabular}{l|l}
\hline Code & \multicolumn{1}{c}{ Telecommunications and information technologies } \\
\hline \multicolumn{2}{|c}{ Torept } \\
\hline 3341 & Computer and Peripheral Equipment Manufacturing \\
\hline 3342 & Communications Equipment Manufacturing \\
\hline 3343 & Audio and Video Equipment Manufacturing \\
\hline 3344 & Semiconductor and Other Electronic Component Manufacturing \\
\hline 3346 & Manufacturing and Reproducing Magnetic and Optical Media \\
\hline 5112 & Software Publishers \\
\hline 5121 & Motion Picture and Video Industries \\
\hline 5122 & Sound Recording Industries \\
\hline 5151 & Radio and Television Broadcasting \\
\hline
\end{tabular}




\begin{tabular}{l|l}
5152 & Cable and Other Subscription Programming \\
\hline 5161 & Internet Publishing and Broadcasting \\
\hline 5174 & Satellite TelecommunicationsT \\
\hline 5179 & Other Telecommunications \\
\hline 5182 & Data Processing, Hosting, and Related Services \\
\hline 5191 & Other Information Services \\
\hline \multicolumn{2}{|c}{ Electronic and vehicular technologies } \\
\hline 3331 & Agriculture, Construction, and Mining Machinery Manufacturing \\
\hline 3332 & Industrial Machinery Manufacturing \\
\hline 3333 & Commercial and Service Industry Machinery Manufacturing \\
\hline 3334 & Ventilation, Heating, Air-Conditioning, and Commercial Refrigeration Equipment \\
\hline 3335 & Manufacturing \\
\hline 3336 & Engine, Turbine, and Power Transmission Equipment Manufacturing \\
\hline 3339 & Other General Purpose Machinery Manufacturing \\
\hline 3345 & Navigational, Measuring, Electromedical, and Control Instruments Manufacturing \\
\hline 3351 & Electric Lighting Equipment Manufacturing \\
\hline 3352 & Household Appliance Manufacturing \\
\hline 3353 & Electrical Equipment Manufacturing \\
\hline 3359 & Other Electrical Equipment and Component Manufacturing \\
\hline 3361 & Motor Vehicle Manufacturing \\
\hline 3362 & Motor Vehicle Body and Trailer Manufacturing \\
\hline 3363 & Motor Vehicle Parts Manufacturing \\
\hline 3364 & Aerospace Product and Parts Manufacturing \\
\hline 3365 & Railroad Rolling Stock Manufacturing \\
\hline 3366 & Ship and Boat Building \\
\hline 3369 & Other Transportation Equipment Manufacturing \\
\hline 5415 & Computer Systems Design and Related Services \\
\hline 8112 & Electronic and Precision Equipment Repair and Maintenance \\
\hline 8113 & $\begin{array}{l}\text { Commercial and Industrial Machinery and Equipment (except Automotive and } \\
\text { Electronic) Repair and Maintenance }\end{array}$ \\
\hline & \multicolumn{1}{|c}{ Bar } \\
\hline
\end{tabular}

\begin{tabular}{l|l}
\hline \multicolumn{2}{c}{ Biotechnologies and medic technologies } \\
\hline 3111 & Animal Food Manufacturing \\
\hline 3119 & Other Food Manufacturing \\
\hline 6214 & Outpatient Care Centers \\
\hline 6215 & Medical and Diagnostic Laboratories \\
\hline 6219 & Other Ambulatory Health Care Services \\
\hline 6223 & Specialty (except Psychiatric and Substance Abuse) Hospitals \\
\hline \multicolumn{2}{c}{ Chemical and pharmaceutical } \\
\hline 3241 & Petroleum and Coal Products Manufacturing \\
\hline 3251 & Basic Chemical Manufacturing \\
\hline 3252 & Resin, Synthetic Rubber, and Artificial Synthetic Fibers and Filaments Manufacturing \\
\hline 3253 & Pesticide, Fertilizer, and Other Agricultural Chemical Manufacturing \\
\hline 3254 & Pharmaceutical and Medicine Manufacturing \\
\hline 3255 & Paint, Coating, and Adhesive Manufacturing \\
\hline 3256 & Soap, Cleaning Compound, and Toilet Preparation Manufacturing \\
\hline 3259 & Other Chemical Product and Preparation Manufacturing \\
\hline 3261 & Plastics Product Manufacturing \\
\hline 3262 & Rubber Product Manufacturing \\
\hline \multicolumn{2}{c}{ Technology based sectors classification: Own elaboration from the NAICS(2007) }
\end{tabular}


In Table 1 it is shown the 15 activities that constitutes the Telecommunications and information technologies sector, it has been excluded the codes 5181, 5171 and 5172 because they refer to internet sellers and telephone services, understanding that these activities are just commercialization of services. It is shown the 22 activities that constitutes the Electronic and vehicular technologies sector, the codes 3361 and 3363 have a especial treatment because of the large sized firms, since they are the big motor vehicle firms on the global context, but also they don't constitute a high technology sector since they just manufactures the vehicles.

Table 2. Description of the variables in the econometric model

\begin{tabular}{l|l|l|l}
\hline Variables & Description & Variable Scale & $\begin{array}{l}\text { Tipe of } \\
\text { variable }\end{array}$ \\
\hline LOG(PROD) & Log of Gross Total Production & Continuos & Static \\
\hline LOG(VA) & Log of Censal Gross added value & Continuos & Dynamic \\
\hline LOG(HOURS) & Log of Hours Worked & Continuos & Static \\
\hline LOG(GFKF) & Log of Gross Fixed Capital Formation & Continuos & Dynamic \\
\hline LOG(PO) & Logaritmo del personal ocupado & Continuos & Static \\
\hline LOG(ACERVO) & Log of Total fixed capital Assets & Continuos & Dynamic \\
\hline SEC1 & Telecommunications and information technologies & 1 if T IT, 0 in other case & Interaction \\
\hline SEC2 & Electronic and vehicular technologies & 1 if EVT, 0 in other case & Interaction \\
\hline SEC3 & Biotechnologies and medic technologies & 1 if B\&MT, 0 in other case & Interaction \\
\hline SEC4 & Chemical and pharmaceutical & 1 if Ch\&Ph, 0 in other case & Interaction \\
\hline TAM1 & Micro Firm & 1 if Micro, 0 in other case & Control \\
\hline TAM2 & Small Firm & 1 if Small, 0 in other case & Control \\
\hline TAM3 & Medium Firm & 1 if Medium, 0 in other case & Control \\
\hline TAM4 & Large Firm & 1 if Large, 0 in other case & Control \\
\hline
\end{tabular}

Own elaboration from the economic census (2004 and 2009), Instituto Nacional de Estadística, Geografía e Informática (INEGI).

As it can be seen, there exist two proxy variables for the production and two proxy variables for the independent variables, by the other side we have two periods (economic census of 2004 and 2009).

Table 3. Firm Classification by employee number and size strata

\begin{tabular}{c|c}
\hline Number of Employees & Firm Size \\
\hline From 0 to $2 ; 3$ to $5 ; 6$ to 10 & Micro \\
\hline From 11 to $15 ; 16$ to $20 ; 21$ to $30 ; 31$ to $50 ; 51$ to 100,101 to 250 & Small \\
\hline From 251 to 500 & Big \\
\hline From 501 to $1000 ; 1001$ and more & Large \\
\hline
\end{tabular}

Own elaboration from the economic census (2004 and 2009), Instituto Nacional de Estadística, Geografía e Informática (INEGI).

In this way, in Table 3 is shown that every strata represents one firm with a specific size, which at the same time can be classified as micro, small, medium and large.

Revista Galega de Economia/ Economic Review of Galicia: https:/ / ideas.repec.org/ s/ sdo/ regaec.html http:/ / www.usc.es/ econo/ RGE/ benvidag.htm 